\title{
"Meninas": VIDAS EM DEVIR NOS CIRCUITOS DE VULNERABILIDADE SOCIAL
}

\author{
Denise Cordeiro ${ }^{\star}$ \\ Eduardo Antônio de Pontes Costa $\star$
}

\begin{abstract}
Resumo
Neste artigo pretendemos discutir, a partir do filme Meninas, de Sandra Werneck, as trajetórias de vida e de trabalho de jovens pobres no Rio de Janeiro, nos circuitos de vulnerabilidade social. As aproximações do olhar cinematográfico vão expressar um "tempo comum", presente no referido documentário, que se materializa em nossas pesquisas: gravidez precoce, violência, desemprego, baixa escolaridade, pouca qualificação e inserção no tráfico de drogas, por exemplo. Nesses circuitos de vulnerabilidade, perguntamos como é possível ampliar a potência de vida dos jovens, que não perdem a possibilidade de escrever sua própria história. É nessa direção que caminha o presente estudo.
\end{abstract}

Palavras-chave: Jovens Pobres. Documentário. Devir.

\section{"Young GIRLs": LIVES BECOMING IN THE CIRCUITS OF SOCIAL VULNERABILITY}

\begin{abstract}
In this article we intend to discuss, based on Sandra Werneck's film Meninas, the life and work trajectories of poor young girls in Rio de Janeiro, in the circuits of social vulnerability. The film, by enabling an updating of the researcher's place to think about the youth condition in the present time, provides a "magical" analytical tool. The cinematographic look approaches express a "common time", present in said documentary, which materializes in our research. In these contexts, we ask how is it possible to expand life potency of youngsters who do not lose the possibility of writing their own history.
\end{abstract}

Keywords: Poor Youngsters. Documentary. Becoming.

^ Professora do Departamento de Educação da Faculdade de Formação de Professores (FFP), da Universidade do Estado do Rio de Janeiro (UERJ), Doutoranda em Educação pela Universidade Federal Fluminense. Endereço: Universidade do Estado do Rio de Janeiro, Rua Francisco Portela, s/no ${ }^{\circ}$ Paraíso, São Gonçalo. CEP: 24435-005

E-mail: cordeiro.denise@gmail.com

$\star \star$ Formação em Psicologia pela Universidade Federal da Paraíba. Professor Substituto do Departamento Sociedade, Educação e Conhecimento da Universidade Federal Fluminense, Doutor em Educação pela Universidade Federal Fluminense.

E-mail:eduapcosta@bol.com.br 


\section{IMAGENS E DIÁLOGOS DIANTE DO OLHAR DO PESQUISADOR}

Imaginar como a vida pode ser narrativa e entrelaçada por outras vidas é pensar mais precisamente em diferentes vozes que o cinema proporciona e atualiza, ao reproduzir imagens, uma nova linguagem visual e imaginária, do ponto de vista de sua criação. O cinema, aqui tomado na acepção de Walter Benjamin (1994), é essa ferramenta que permite ao homem representar a si mesmo e ao mundo que o cerca.

Representar, no sentido de falar sobre um tempo contemporâneo, à medida que o cinema permite falar desse mesmo tempo, não em um sentido estéril, de uma produção de si, de uma subjetividade que se traduz apenas por um olhar técnico. O cinema, por sua dimensão histórica, nos permite falar, também, daquilo que é do domínio da arte. Valendo-se de Franz Werfel, Benjamin (1994, p. 177) afirma que o cinema ainda não encontrou seu verdadeiro sentido: “[...] Seu sentido está na sua faculdade característica de exprimir, por meios naturais e com uma incomparável força de persuasão, a dimensão do fantástico, do miraculoso e do sobrenatural".

O surgimento do cinema permitiu, assim como o da fotografia, no mundo contemporâneo, outras formas de produção de conhecimento. Como uma nova indústria de imagens, proporcionou e atualizou uma nova linguagem, outra estética sobre a vida que se objetiva e subjetiva. Um novo aparato que, também, se traduz num novo organizador da percepção, proporcionando as transformações do sensorium, dos modos de perceber e de experimentar a vida. Para Benjamin (1994, p. 194): “[...] O cinema se revela assim [...] o objeto atualmente mais importante daquela ciência da percepção que os gregos chamavam de estética”.

Desse modo, podemos afirmar que o cinema consegue tornar visível o que não víamos, como também, permite atualizar o olhar do pesquisador-espectador, ao recordar e ao discutir, em especial, sobre algumas narrativas juvenis em que as tramas de suas vidas são tecidas pelas lentes do documentário $\mathrm{Me}$ ninas, de Sandra Werneck (2005). Trata-se, certamente, de uma ferramenta de afetações - o cinema. Enfim, o que salta à vista do pesquisador? As ambivalências e reflexões, sinalizadas no filme, mobilizam outras transgressões de nosso olhar, ao adentrarmos no conflito dialético que o cinema produz, em especial, na nossa realidade imagética.

Se, para Benjamin (1994), o filme pode servir para "lançar" o nosso olhar para novas percepções e reações produzidas a partir de uma técnica que cada vez mais expressa a vida cotidiana, entendemos, portanto, que o filme, especificamente, do tipo documentário, é, também, uma ferramenta analítica "mágica" que propicia reatualizações do lugar do pesquisador, para pensar a condição juvenil no tempo presente e as aproximações do olhar cinematográfico em direção às nossas pesquisas sobre trajetórias de vida e de trabalho de jovens pobres no Rio de Janeiro. A visibilidade no documentário Meninas expressa uma narrativa, uma produção de subjetividade, que também se aproxima dos jovens presentes em nossas pesquisas, e que se encontram nos circuitos de vulnerabilidade. 
Quando o cinema torna visível aquilo que não víamos, como nos afirma Benjamin (1994), para nós, a visibilidade no documentário Meninas expressa uma narrativa, uma produção de subjetividade, que também se aproxima, respeitando-se as devidas especificidades, dos jovens pesquisados por nós, em áreas pobres do Rio de Janeiro.

Diante dessas considerações, indagamos por que esse documentário Meninas? Em que medida ele nos faz pensar a pesquisa? O cinema produz um deixar levar-se, libertando as emoções. Não é que o cinema seja em si algo novo, mas ele nos faz pensar e nos remete aos processos de produção da "fabulação dos pobres" que não traz consigo uma lenda ou um animal mítico, porém a vida cotidiana, com seus enfrentamentos diversos, suas ambições e desejos, resistências etc. (GUIMARÃES, 2001). Imersos na vida cotidiana, em meio aos seus dilemas e desafios, mais do que uma questão estética, ao discutir a diferença entre a "fabulação do outro" e a "ficção sobre o outro", Guimarães afirma que se trata de uma questão ética que o cinema busca soluciona, a partir das experiências de que dispõe.

Enfim, como o outro expressa ele mesmo e uma relação? Entendemos que o referido documentário permite falar sobre si e sobre os outros. Nessa mesma direção, acreditamos, em nossas pesquisas, ser importante que o outro fale de si, fabule de si. Em Benjamin (1994) e Deleuze (1992), cada um a seu modo, há a ressignificação da experiência, há o devir da imanência. O cinema nos permite "escutar o eco das vozes", como afirma Benjamin, (1994) sobre o preceder, algo que lampeja do presente, passado e futuro em oposição ao tempo cronológico. Assim, aqui a fabulação permite ao jovem ressignificar sua história, ao subverter os modelos hegemônicos de viver, de pensar, de sentir.

Nesse sentido, César Guimarães (2001), ao discutir "fabulação dos pobres", a fabulação do outro (construída pelo documentário), parte de um olhar policêntrico, de um mundo sem cenários com identidades fixas. A alteridade, no cinema, aparece, quando o cineasta capta um olhar que desnaturaliza, que transgride a formatação limítrofe de classe, de gênero, de etnia, por exemplo.

O documentário traz o outro que fala, mas fala como de si? É um olhar insurgente. Aqui, o cinema nos permite elaborar uma interseção com o rosto, com o entrevistado em sua singularidade ontológica, que vibra, descentra pelo afeto. É assim que o afeto é o caminho possível das meninas enfrentarem dilemas tão difíceis. Os rostos expressam um desafio de compreensão: onde ficam os traços que fazem a diferença pelas escolhas, resistências, ambições?

O referido documentário apresenta histórias de vida de quatro jovens grávidas e pobres, entre 13 e 15 anos, moradoras de algumas favelas do Rio de Janeiro. A cineasta propõe, a partir do cotidiano das meninas, entender a constituição da menina-mãe e a sua relação com os pais e namorados. Elas freqüentam o baile funk, têm parentes na igreja, conhecem jovens traficantes e são, em determinados momentos, aparentemente tímidas. 
A cineasta procura mostrar, ao mesmo tempo, numa postura contundente e delicada, os diferentes modos de existir das meninas, mesmo vivenciando histórias semelhantes, e suas expectativas em torno do devir-mulher-mãe. Trata-se, portanto, de um retrato cruel de uma realidade amarga para jovens pobres, cuja gravidez parece interromper as poucas oportunidades de escolhas, a interrupção dos estudos ou do trabalho, quando elas ficam grávidas inesperadamente.

Como cada família lida com a gravidez precoce, também, se configura em elemento importante para o documentário. Numa família, é flagrante a gravidez de uma mãe pouco tempo depois de sua filha ter engravidado também, evidenciando a ausência dos pais das futuras crianças.

Em suma, o filme proporciona aos nossos olhares um entrelaçamento de histórias de vida, de amor entre jovens, em que os conflitos familiares, ora são traduzidos por cenas de ciúmes, de incompreensão, de tensão, de medo, ora por "aceitação", quando as futuras avós partilham a alegria, a solidariedade, à medida que vão organizando a vida coletiva em torno da chegada das crianças.

\section{Circuitos de vulnerabilidade social e as fabulações do outro}

Para Luana, 15 anos, moradora do Morro dos Macacos, a gravidez, "quando aconteceu, aconteceu". Logo no início do filme, ela mostra as roupas do seu bebê. Tão jovem e já atravessada pela condição precoce de menina-mulher. Assistir à entrevista de Luana, no cinema, leva-nos a pensar na Raiane, outra jovem de 16 anos moradora do bairro do Jardim Catarina, em São Gonçalo, um de nossos locus de pesquisa. Assim como Luana, também essa última jovem, ao ser perguntada sobre o que achava de estar grávida, disse: "Bem que eu não queria, mas já que veio. Qué vê? Olha só as roupinhas". Nesse momento, Raiane abre um armário e mostra alguns sapatinhos de bebê, verdes, amarelos. O mesmo gesto de Luana. O que carrega esse gesto? Por que expor as roupas de bebê? Talvez, o gesto traga a imaginação de uma vida em cor-de-rosa, cheia de inocência e leveza. Mas será que a vida delas carrega essa experiência? Quantas interdições ser mãe, a gravidez já anuncia, contrariando a leveza das cores de bebê, os tecidos aconchegantes e suaves? A vida dessas meninas está longe de ser em cor-de-rosa.

A gravidez não facilitará os caminhos de vida e a produção de "campos de possibilidades" (VELHO, 1999). Ao contrário disso, gera novas desigualdades que se somam àquelas que já vividas, inerentes à condição de classe.

Luana e Raiane, nunca se conheceram, mas ambas, não por acaso, estão cada vez mais longe da escola. Luana luta para freqüentar as aulas numa escola noturna, diante das dificuldades do bebê que já nasceu. Raiane já saiu da escola, ainda na $7^{\mathrm{a}}$ série, e combinou com o namorado que "um ano e meio depois do bebê nascer, voltará a estudar". Será? A precocidade de ser mãe, que ainda não atingiu um patamar mínimo de auto-suficiência econômica, afetiva, o que amplia a produção da dor, e da crueldade de vida dessas meninas, Joanas, Claras, Marias, Antônias, presentes na reprodução da pobreza e da exclusão social nas mais diversas cidades desse país. 
Na Rocinha, Evelin, 13 anos, afirma que é melhor ser mãe mais jovem, porque assim o filho "vai crescendo junto, vai curtindo". O namorado, do "movimento", diz que vai sair do tráfico para criar o filho. As dificuldades de vida somadas à precariedade para ampliar e concretizar um projeto de futuro se apresentam como difíceis saídas para esses jovens. A gravidez se materializa num contexto de forte culpabilização e interdição social. Como se sustentar fora do tráfico, que é uma verdadeira economia submersa e paralela ao poder público? Viver de quê? Que alternativas se configuram para esse jovem, numa vida que já se anuncia curta, pois a possibilidade de morrer num confronto com a polícia ou com outros grupos rivais se faz muito presente? Qual a perspectiva de vida de Evelin e seu filho nessa trama de vulnerabilidade social?

Em Engenheiro Pedreira, Joice, de 15 anos, menina tímida, com as mãos sobre o colo, retorcendo os dedos, num gesto repetido, conta sua história. Apaixonada por Alex, de 21 anos, engravida e enfrenta a solidão, já que não encontra no namorado, nem na família a possibilidade do diálogo, dos afetos. Deixada pelo namorado, que volta para um relacionamento anterior, tem de encarar esse difícil momento. $\mathrm{O}$ dilema de viver a transição para a vida adulta em condições de gerar uma nova vida não é nada fácil ao acentuar um sentimento de insegurança e de precariedade presente na condição juvenil de nosso tempo presente.

Na Rocinha, Edilene, de 13 anos, é o outro elo desse triângulo amoroso, também grávida de Alex. A mãe de Edilene, sentada ao seu lado na sala de casa, conta que transou sem camisinha, engravidou sem querer, pois achava que não seria mais capaz de ser mãe. O bebê-tio será criado junto com o sobrinho-irmão, principalmente pela Edilene, já que a mãe tem de voltar ao trabalho para manter o sustento da família e o pai não irá assumir a criança. A mãe de Alex, conta no filme, que, também, foi mãe aos 16 anos.

As histórias se repetem como uma "sina", uma profecia auto-realizadora na vida dessas mulheres, alimentada pela ausência de políticas públicas e pela falta de garantia dos direitos sociais da população juvenil mais pobre, gerando a perpetuação da pobreza. Evidentemente que a gravidez não planejada acontece em diferentes segmentos sociais. O que está em debate, aqui, é a maneira específica de concretizar esse momento na vida da jovem grávida, muito mais vulnerável pela ausência do Estado e com parcos recursos de apoio familiar, igualmente aviltada socialmente.

Nesse contexto de vulnerabilidade social, as contradições apontadas pelo documentário evidenciam, certamente, um tipo de sociedade que se forjou em nosso país, quando afunilamos nossas lentes a partir das pesquisas de Abramovay \& Pinheiro (2003), Abramo (1997), Sposito (2003), Dubet (2001). Esses autores nos ajudam a compreender a juventude como experiência plural e multifacetada, produzida por novas desigualdades expressas pela condição de gênero, etnia, possibilidade ou não de ingresso no mercado de trabalho formal. 
Assim é na vida cotidiana, capturados, nós-pesquisadores, pelas imagens produzidas em Meninas, que podemos vislumbrar um espaço importante de expressão social da juventude pobre, produzida em circuitos de vulnerabilidade social, essa entendida como:

[...] o resultado negativo da relação entre a disponibilidade de recursos (materiais ou simbólicos) dos atores e o acesso à estrutura de oportunidades sociais, econômicas, culturais que provêem do Estado, do mercado e da sociedade civil (ABRAMOVAY; PINHEIRO, 2003, p. 1).

O futuro pai dos filhos de Edilene e de Joice, Alex, por sua vez, reclama que a vida ficou diferente. Antes, quando "solteiro", podia dançar, cantar, ir aos bailes. Agora, duplamente pai, pesa sobre ele a responsabilidade de contribuir financeiramente com as duas "jovens-mulheres-mães" de seus filhos. O salário que recebe, trabalhando numa fábrica de móveis, vai quase todo para sustentar os bebês, ainda mesmo durante a gravidez, na compra de enxovais, por exemplo. O trabalho de Alex exige uma qualificação mínima, que não é reforçada pela continuidade nos estudos. Estudar e ampliar os projetos de vida nem se anunciam em seu horizonte de vida. Trabalhar para sobreviver é o caminho possível diante da produção de sua existência. Além do trabalho, Alex passa a freqüentar uma igreja pentecostal em que encontra apoio para enfrentar a difícil jornada. Aqui, a fé aparece como resposta e conforto diante dos dilemas que atravessam a experiência de ser, duplamente, pai.

São movimentos de resistências? Estariam os jovens produzindo caminhos menos visíveis de experiências significativas diante dos desafios com que se deparam? Meninas, em cada singularidade, não poderia expressar práticas cotidianas, táticas subversivas de sobrevivência em seus pequenos e delicados desvios? Essas estratégias de sobrevivência ou de vida, exacerbadas pelas "desigualdades multiplicadas", apontariam para a participação possível dos sujeitos pela forma como se tornam visíveis na sociedade civil, diante de uma suposta "proteção social"?

Em síntese, falar em juventude como categoria analítica pressupõe romper com uma aparente homogeneização, implicando considerar, como diversidade, seus pertencimentos sociais, seus campos de interação e ocupação do espaço urbano. Pretendemos escapulir de uma visão mítica da juventude, totalizante e estática que pouco ajuda a compreender sua condição, num tempo presente, marcada por desigualdades, não apenas de classe, segundo a análise de Dubet (2001), ao se referir a uma produção cada vez mais acentuada das "desigualdades multiplicadas", mais sutil e excludente. Aqui, cabe indagar, ao mesmo tempo em que se "multiplica" essa desigualdade, não estaria subtraindo um campo de pertencimento do outro, nesse caso, dos jovens pobres? Os exemplos do referido autor ganham visibilidade para as nossas análises, ao mencionar um tipo de equações perversas pela produção de segregação, ao estudar os jovens, filhos de imigrantes na França, que, de forma paradoxal, são assimilados pela sociedade francesa, mas não integrados. 
De forma geral, é multiplicada também, quando não implica apenas a determinação de uma condição de classe. Sobre o emprego formal, ainda na França, afirma Dubet (2001, p. 12), que a distribuição das desigualdades entre as faixas etárias transformou-se acentuadamente nos últimos 30 anos. "[...] Os jovens são mais atingidos pelo desemprego que os adultos e, sobretudo, estão condenados a um longo período de incerteza e de precariedade antes de conseguirem um emprego estável [...]”. Diante dessas considerações, ao parafrasear Bauman (1998), perguntamos: estaríamos vivendo uma sensação de um novo tipo de incerteza numa condição pós-moderna?

Sobre esse aspecto, Bauman (1998) irá situar o debate da pós-modernidade, ao afirmar a existência de uma sociedade marcada por um tempo-espaço flexível, em constante mudança, em que a habilidade de se mover do outro vai-nos falar mais de contextos históricos nos quais "turistas e vagabundos" - metáfora para explicar quem são os heróis e as vítimas do capitalismo flexível (HARVEY, 1994) - são produzidos numa busca constante por certo tipo de "pureza". Segundo Bauman (1998, p. 26):

[A] busca da pureza moderna expressou-se diariamente com a ação punitiva contra as classes perigosas; a busca da pureza pós-moderna expressa-se diariamente com a ação punitiva contra os moradores das ruas pobres e das áreas urbanas proibidas, os vagabundos e indolentes.

As ambivalências e reflexões derivadas nas narrativas autobiográficas apontam em duas direções: transgredir a nossa leitura em relação à condição juvenil nos dias atuais; e elaborar aproximações do olhar cinematográfico em direção às nossas pesquisas. Notadamente, um "tempo comum" que se expressa, também, no referido documentário que denuncia, também, um tipo de pobreza que se produz e circula em parte de uma realidade da cidade do Rio de Janeiro: gravidez precoce, violência, desemprego, situações de abandono, baixa escolaridade, pouca qualificação, inserção no tráfico de drogas etc.

É nessa perspectiva, que nos parece significativo recuperar, pelo olhar cinematográfico, as trajetórias autobiográficas narradas pelos jovens em cena, como sinalizações de seus campos de ação (GIDDENS, 1994), de seus dilemas e encontros com a vida.

Giddens (BECK; GIDDENS; LASH, 1997) ressalta os campos de ação como espaços de ação interpretativa, isto é, como um intrincado e diferenciado movimento de compreensão dos contextos dos indivíduos, isto é, aqueles associados à experiência do cotidiano (as normas, os "sentidos de orientação", mapas de significação por eles elaborados no que toca ao cotidiano) e dos contextos analíticos, isto é, aqueles elaborados e construídos pelo conhecimento científico (a fabricação das explicações científicas dos fenômenos que nos integram). Isso ocorre quando pensamos a juventude retratada no documentário Meninas e em nossas pesquisas, nessa dupla hermenêutica analítica: como um problema social 
(um sinalizador das formas de expressão e desafios que os jovens atravessam) e como problema de investigação sociológica (a compreensão dessa mesma juventude e os sentidos por ela produzidos).

As três últimas décadas do século XX, em especial, a partir dos anos de 1990, nos ajudam a compreender que, diante da crise do capital e da aparente desmobilização política, o jovem pode estar expressando uma crise de produção de sentidos e de garantia de direitos. A participação juvenil, aparentemente oca na luta pela conquista dos direitos conclamados na nossa Constituição Cidadã de 1988 e no Estatuto da Criança e do Adolescente (ECA) de 1990 está na ordem do dia, e também é extremamente válida.

Contudo, os jovens pobres, fabulados no documentário, apontam para uma suposta desagregação dos serviços e instituições públicas que não são capazes de proporcionar as funções básicas quando nos referimos aos bens coletivos: educação, saúde, trabalho, habitação, etc. Esse contexto fica evidente numa passagem do documentário em que as meninas estão sentadas e enfileiradas, num laboratório, para exame-teste de gravidez. Apenas no desenrolar das histórias, é possível identificar o espaço onde os exames seriam realizados, pertencente a uma suposta entidade não governamental. Portanto, é visível a redução ou a inexistência de um "Estado-providência" (DUBET, 2001), o que, por seu turno, não inviabiliza os arranjos e rearranjos que elas e suas famílias conseguem produzir, em específico, frente às alternativas de vida e de trabalho. Certamente, essa mesma sociedade produz maior impacto sobre os jovens que se encontram nessa condição, definida por Bauman (1998), como os "estranhos". A diluição do Estado e a reprodução da pobreza, na condição pós-moderna, vêm reafirmar a produção dos jovens pobres, percebidos como os "descartáveis".

Ainda sobre essa questão, Abramo (1997), ao analisar o entendimento social do conceito de juventude no Brasil, é contundente ao afirmar que a tematização da juventude brasileira é percebida como emblema dos "problemas sociais". Sobre a juventude pobre, há uma visibilidade, a partir dos anos 1990, sobre aqueles que aparecem nas ruas, enviesados, atravessados, no fluxo quase contínuo dos carros e dos transeuntes. As análises sociais têm privilegiado a juventude pobre urbana como seu objeto de estudo. Eles são os infratores, as gangues, as galeras, tribos, e, notadamente, jovens em "situação de risco" para si e para a ordem social, "[...] dos quais aqueles envolvidos no tráfico, matando e morrendo muito cedo, são uma das imagens mais dramáticas e ameaçadoras dos nossos tempos" (ABRAMO, 1997, p. 33). Os estudos, ainda sobre a referida temática, dirigem a nossa atenção para a análise do mercado de trabalho formal e informal (em que buscam uma inserção em atividades marginais). No campo educacional, há, também, a presença de pesquisas sobre evasão, fracasso escolar e drogadição. Diante dessas considerações, como entender, nesses circuitos de vulnerabilidade, a produção de identidades juvenis? 
"Meninas": vidas em devir nos circuitos de vulnerabilidade social

\section{Múltiplas TRajetórias daS MENinas E dOS MENinOS}

A juventude ou juventudes exacerbam, como expressão do tempo presente, os principais problemas da pós-modernidade pela diversidade de formas de expressão de si. Sobre a questão da construção de identidades múltiplas num mundo pós-moderno, Bauman (1998, p. 114) vai afirmar que o "[...] eixo da estratégia de vida pós-moderna não é fazer a identidade deter-se - mas evitar que se fixe". Quando pensamos nos jovens, acreditamos que a expressão subversiva relacionase à construção de um ser jovem que não se fixa a um modelo "único" de sentir e perceber o mundo, mas ao produzir a vida a partir de fluxos, de intensidades, que desconstruam essa noção de "tempo flexível", globalizado, e cada vez mais excludente. Destacamos que a afirmação de Bauman se refere - na metáfora entre turistas e vagabundos - à figura do turista como o resumo dessa "evitação" - "evitar que se fixe", pois não pertencem ao lugar que estão visitando. A vida não é uma "bolha", trancada em si mesmo, como assinala o referido autor.

Percebemos que desafios diversos atravessam a vida em Meninas e também, são conectados com o fenômeno relacional das identidades juvenis nos dias atuais. Os movimentos culturais de resistência (JAMESON, 1994), em especial aqueles produzidos pela juventude, são um caminho possível para subverter a produção de modos hegemônicos de sentir e viver o mundo, em que o outro é percebido, ora como "estranho" pela modernidade, ora atualizado como "descartável” por uma condição pós-moderna.

Toda palavra carrega sentidos e luta em torno deles (BAKHTIN, 1992). Por vezes mal interpretado, no campo das ciências sociais, ou de fato, reduzido a um jargão de homogeneizações, o termo identidade merece uma reflexão. Para nós, as identidades só cabem em termos plurais e configuram-se como um conceito "relacional", pois o jovem se expressa de modo heterogêneo nas formas de apropriação, e de luta pelo direito à cidade (REGUILLO, 1998). As mais diversas expressões culturais juvenis são um sinal dessa dinâmica: as bandas de trash, hiphop, funk, os grafiteiros, os punks, e muitos outros grupos juvenis redesenham e matizam de diferentes cores a favela, o bairro, a cidade, enfim, o espaço urbano. Os jovens fazem parte de bandas, participam de igrejas, vão à escola, se encontram com os amigos na rua, estão nos partidos, protagonizam grupos e associações peculiares. Mellucci (1992) salienta que a noção de identidade, mais do que um dado de essência ou uma herança do sujeito, é produto de nossas ações. Assim, podemos perceber as identidades juvenis como um sistema de relações e de produção de sentidos: pessoal, familiar, social. Isso significa dizer que os jovens vivem uma multiplicidade de experiências e possuem diversos pertencimentos que influenciam na constituição de suas subjetividades.

Giddens (1994), ao discutir uma política de identidade, explica que quanto mais "fazemos a nós mesmos" como humanos, mais caminhamos em direção à reflexividade, isto é, atuarmos historicamente para fazermos, nós mesmos, na relação com os outros, a história. A reflexividade coloca como uma experiência pessoal e política, o jovem em foco, especialmente nos luminosos momentos em que exercita a fabulação de si mesmo. Acreditamos que o reconhecimento do 
sujeito que se faz, acontece em Meninas, quando, por exemplo, Evelin dança na laje de casa, com sua mãe numa festa familiar. Evelin, aparentemente bela, alegre e plena de si, constrói um lampejo de memória, fundada no afeto e na fabulação de si, que pode servir para enfrentar os difíceis momentos da gravidez.

Procuramos enxergar os próprios jovens que irrompem formas de resistência e sobrevivência na vida cotidiana. Ser jovem, nesse contexto, é estar vivendo pertencimentos permanentemente em trânsito, nas múltiplas identidades, ser mãe, ser filha, ser estudante. Em todas elas, deparando-se com as "infidelidades do meio", segundo Canguilhem (apud CAPONI, 1997). Essas experiências são elaboradas nas políticas de escolhas possíveis dos jovens, e dizem respeito à maior ou menor possibilidade de autonomia dos sujeitos, porque há, também na dimensão de vida pessoal, uma face política de intercâmbio entre a história pessoal e a sociedade e o fazer histórico (GIDDENS, 1994).

Se tomarmos o documentário como ponte reflexiva, mais uma vez, as escolhas do sujeito são registros de ambivalências entre um modelo de juventude globalizada em contraste com a gravidez realizada. Embora o filme explore pouco o tema da identidade pessoal (Quem sou eu? Quais são minhas redes de conectividades?) - é pelas relações familiares, que as ambivalências da identidade se apresentam. O que se espera dos jovens? A sociedade produz um modelo hegemônico de modos de sentir, de pensar, de viver, "mais adequado" em relação a eles. No entanto, por exemplo, quando olhamos o gênero, meninas que vêm de uma condição de pobreza, têm de lidar com os enquadramentos de filiação social, ao mesmo tempo em que podem rejeitar esses mesmos modelos. No tempo presente, mais e mais meninas rompem com o modelo cultural e engravidam, quer seja pelo excesso de estímulos, diminuição do tempo da infância, quer seja pela permeabilidade de trânsito no mundo dos adultos. Muitas tomam as interdições como um estímulo e uma fronteira a ser vencida, de modo que experimentar a sexualidade pode ser uma forma de romper ou aderir a certo modelo de identidade juvenil global. Se acreditarmos que, quando engravidam, subvertem uma ordem moral, isso acarreta um impacto em suas vidas, de cunho específico, por serem pobres e mais vulneráveis socialmente, já que a família e a sociedade passam a encará-las como um problema a ser solucionado. Isso seria uma emancipação precária que se produz em nome do prazer do corpo. Aqui, não há um desfecho que possa expressar um fim de história. Mais e mais meninas, para além de Meninas, são imagens cheias de movimento e colorido, de difícil apreensão, exigentes em seus enquadramentos e enfrentamentos de vida.

\section{Conclusão}

Buscamos discutir, nesse artigo, a partir do documentário Meninas, de Sandra Werneck, as trajetórias de vida e de trabalho de jovens pobres no Rio de Janeiro, nos circuitos de vulnerabilidade social. Esse documentário proporciona uma janela de reflexão sobre a condição social do jovem. As imagens e as narrativas sinalizam para a ampliação das desigualdades sociais e para a falta de apoio na solidez de projetos de vida desses jovens. 
As vidas juvenis expostas na tela traduzem a diluição do Estado e a reprodução da pobreza na condição pós-moderna, sendo atreladas, certamente, às políticas neoliberais de constituição de um Estado-mínimo, ao reafirmarem a produção de jovens pobres percebidos como os "descartáveis".

O que produz uma gravidez precoce? Como lidar com as informações diante de um desejo que requeira alguma orientação? Os jovens em tela enfrentam uma multiplicidade de conflitos e desafios complexos entre ter, assimilar e considerar valores de vida. A família, os grupos de amigos, os projetos de futuro estão ali colocados por uma sociedade que, simultaneamente, reprime e alimenta o consumo, pela experiência da sexualidade. E expressivo, no documentário, que a gravidez precoce não facilita os caminhos de vida e a produção de campos de possibilidades. Ao contrário disso, propicia a produção de novas desigualdades que somadas à realidade dos jovens traduz o lugar social que ocupam.

$\mathrm{Na}$ condição de espectadores e pesquisadores, somos afetados pelas ambivalências e pelas reflexões derivadas das narrativas autobiográficas que mobilizam apontar em duas direções: transgredir a nossa leitura sobre a condição juvenil não-linear na contemporaneidade e elaborar aproximações do olhar cinematográfico em direção aos nossos estudos, ou seja, a intensa reafirmação da reprodução da pobreza e o rompimento epistemológico em relação aos estudos que enfatizam uma visão monolítica da juventude brasileira.

\section{REFERÊNCIAS}

ABRAMO, H. W. Considerações sobre a tematização social da juventude no Brasil. In: Juventude e Contemporaneidade. São Paulo: Revista Brasileira de Educação, ANPED, n. 5 e 6, 1997.

ABRAMOVAY, M.; PINHEIRO, L. C. Violencia e vulnerabilidad social. In: FRAERMAN, A. (Org.). Inclusión Social y Desarrollo: presente y futuro de La Comunidad IberoAmericana. Madri: Comunica, 2003. p. 161-166.

BAKHTIN, M. Marxismo e filosofia da linguagem. São Paulo: Hucitec,1992.

BAUMAN, Z. O mal-estar da pós-modernidade. Rio de Janeiro: Zahar, 1998.

BENJAMIN, W. Obras escolhidas I: magia e técnica, arte e política. São Paulo: Editora Brasiliense, 1994.

BECK, U.; GIDDENS, A.; LASH, S. Modernidade Reflexiva: trabalho e estética na ordem social moderna. São Paulo: Unesp, 1997.

CAPONI, S. Georges Canguilhem and the epistemological status of the concept of health. História, Ciências, Saúde, Rio de Janeiro, v. IV, n. 2, p. 287-307, 1997.

DELEUZE, G. Conversações. Rio de Janeiro: Ed. 34, 1992. 
DUBET, F. As desigualdades multiplicadas. Revista Brasileira de Educação, São Paulo - ANPED, n. 17, 2001.

GIDDENS, A. Modernidade e Identidade Pessoal. Oeiras (Portugal): Celta, 1994.

GUIMARÃES, C. G. O rosto do outro: ficção e fabulação no cinema segundo Deleuze. In: LINS, D. (Org.). Pensamento nômade: Nietzsche e Deleuze. 1 ed. Rio de Janeiro: Relume Dumará, 2001, p. 81-93.

HARVEY, D. A condição pós-moderna. São Paulo: Loyola, 1994.

JAMESON, F. Espaço e imagem: teorias do pós-moderno e outros ensaios. 4. ed. Rio de Janeiro: UFRJ, 1994.

MELLUCCI, A. Il giocco dell'io. Milão: Saggi/Feltrinelli, 1992.

MENINAS. Direção: Sandra Werneck. Assistente de direção: Gisela Camara. Produção: Luis Antonio Silveira. Rio de Janeiro: Videofilmes, 2005. 1 DVD (71 min.). Gênero: documentário.

REGUILLO, R. El año mil, ética, política y estéticas; imaginários, adscripciones y prácticas juveniles. Caso mexicano. In: MARGULIS, M. (Org.). Viviendo a toda: jóvenes, territórios culturales y nuevas sensibilidades. Bogotá: Siglo Del Hombre, Departamento de Investigaciones Universidad Central, 1998. p. 57-82.

SPOSITO, M. P. Os jovens no Brasil: desigualdades multiplicadas e novas demandas políticas. São Paulo: Ação Educativa, 2003.

VELHO, G. Projeto e Metamorfose: antropologia das sociedades complexas. 2. ed. Rio de Janeiro: J. Zahar, 1999.

Recebido em: maio de 2007

Aceito em: fevereiro de 2008 